\title{
Patterns of Crowding of the Anterior Tooth Germs in the Fetal Life
}

\author{
By \\ Tadahiro Ooë \\ Department of Anatomy, University of Tokyo Faculty of Medicine
}

The aim of the author's first study (published in 1956) was to explain from the embryological view point the queer phenomenon of lingual eruption of the lateral incisor. The author presupposed in that paper that the type of shifting of that tooth to the lingual side differs between the maxillary and the mandibular jaws: in the maxillary jaw the germ of lateral incisor is located on the lingual side as a whole (Fig. 1-A), while in the mandibular jaw the germ of lateral incisor is rotated with its distal portion located lingually (Fig. 2-B).

However, through scanning a number of jaws it was noticed that the pattern and grade of the shift of the deciduous lateral incisor varied from specimen to specimen. In the present paper, therefore, this problem is again dealt with from the statistical point of view.

\section{Materials and Method}

Materials consist of human foetuses listed in the previous papers $(1956,-62)$. In addition to the method used in the previous studies, which was the examination of serial sections and reconstructed models, the author examined the tooth germs with the naked eye and observed radiograms of tooth germs.

\section{Observations and Discussion}

1. Classification of patterns through scanning horizontal sections.

Through the scanning of horizontal sections, it was noticed that there were three types in the arrangement of the deciduous anterior tooth germs.

The first type was described in a previous paper (1956) as the most common arrangement in the maxilla: the lateral incisor as a 
whole is located linguad, so that the mesio-distal diameter of its crown is parallel to the curve of the dental arch. In this paper, this type is called type A and shown in Fig. 1-A (=Fig. 22, 1956) and Fig. $2-\mathrm{A}$.

The second type was described (1956) as the characteristic type of the mandible (1956), illustrated in Fig. 1-B (=Fig. 11, 1956) and Fig. 2-B. In this type the lateral incisor is rotated with its distal part turned to the lingual side. This type is termed type B.

The third type is demonstrated in Fig. 1-C and Fig. 2-C. The germ of the lateral incisor is rotated in the direction opposite to that of type B: the mesial portion of the tooth germ is turned to the lingual side. This type will be treated as type C.

Since the incisor germs grow remarkably in the 5th fetal month, as stated in a previous paper (1963), the crowding becomes very conspicuous after the 6 th fetal month. Therefore, the result of the observation is listed below only for the latter half of fetal life. The jaws with anomalous conditions are listed with special notification. Transitional cases which were difficult to be identified as A or C are shown with an asterisk sign.

\begin{tabular}{|c|c|c|c|c|c|c|}
\hline $\begin{array}{l}\text { Fetal } \\
\text { month }\end{array}$ & $\begin{array}{l}\text { Number of } \\
\text { embryo }\end{array}$ & $\begin{array}{l}\text { Crown-rump } \\
\text { length }(\mathrm{cm})\end{array}$ & & Ipper jaw & & Lower jaw \\
\hline \multirow[t]{4}{*}{ V } & 17 & 11.0 & A & A & A & A \\
\hline & 6 & 12.1 & B & $\mathrm{B}$ & B & B \\
\hline & 12 & 12.5 & A & & B & \\
\hline & 32 & 13. 2 & A & A & B & B \\
\hline \multirow[t]{7}{*}{ VI } & 30 & 16.0 & A & $C^{*}$ & $\mathrm{~B}$ & B \\
\hline & 9 & 16.5 & A & $\mathrm{A}$ & B & B \\
\hline & 13 & 17.0 & A & $\mathrm{C}^{*}$ & B & (fetal eruption) \\
\hline & 10 & 17.5 & C & & $\mathrm{C}$ & \\
\hline & 36 & 18. 0 & A & A & B & B \\
\hline & 31 & 19.0 & A & $C^{*}$ & B & (fused) \\
\hline & 16 & 19.2 & C & $\mathrm{C}$ & B & B \\
\hline \multirow[t]{7}{*}{ VII } & 45 & 20.0 & A & $\mathrm{C}$ & B & $\mathrm{C}$ \\
\hline & 49 & 20.0 & A & (fused) & B & $C\left(i_{1} \text { winging }\right)^{* *}$ \\
\hline & 15 & 21.0 & A & & B & \\
\hline & 14 & 22.0 & A & A & B & A \\
\hline & 56 & 23.0 & A & & B & \\
\hline & 41 & 23.0 & $\mathrm{C}$ & A & B & B \\
\hline & 50 & 23.0 & A & A & B & B \\
\hline \multirow[t]{2}{*}{ VIII } & 47 & 24.0 & A & $\mathrm{A}$ & B & B \\
\hline & 48 & 25.0 & A & $\mathrm{A}$ & B & $C\left(i_{1} \text { winging }\right)^{* *}$ \\
\hline
\end{tabular}




\begin{tabular}{|c|c|c|c|c|c|c|}
\hline & 51 & 26.0 & A & $\mathrm{C}$ & B & $\mathrm{B}$ \\
\hline & 63 & 26.0 & B & (extra teeth) & B & $\mathrm{B}$ \\
\hline & 66 & 26.0 & $A^{*}$ & $\mathrm{C}$ & B & B \\
\hline \multirow[t]{4}{*}{ IX } & 62 & 28.0 & $\mathrm{~B}$ & B & B & $\mathrm{B}$ \\
\hline & 58 & 28.0 & A & C & B & $\mathrm{B}$ \\
\hline & 64 & 29.0 & $\mathrm{C}$ & $\mathrm{C}$ & B & B \\
\hline & 34 & 29.0 & A & & B & \\
\hline \multirow[t]{7}{*}{$\mathrm{x}$} & 65 & 29.5 & A & A & A & B \\
\hline & 60 & 30.0 & $\mathrm{~A}$ & $A^{*}$ & B & B \\
\hline & 61 & 30.0 & $\mathrm{~B}$ & B & B & $A^{*}$ \\
\hline & 67 & 31.0 & $\mathrm{~A}$ & $\mathrm{~A}$ & B & $\mathrm{C}$ \\
\hline & 27 & 31.0 & $\mathrm{C}^{*}$ & & B & \\
\hline & 59 & 32.0 & $\mathrm{~A}$ & A & B & B \\
\hline & 57 & 32.5 & $\mathrm{C}$ & C & B & $\mathrm{B}$ \\
\hline
\end{tabular}

** See Da hlberg, A. A., Analysis of the American Indian Dentition. Dental Anthropology, Pergarmon press, P. 156, 1963.

Schwarz, M. (1933) and Cadenat, H. (1952) have already studied the crowding of anterior tooth germs in the fetal life by means of radiography.

As for the upper jaw, the author's type A and B correspond respectively to $C$ ad e $n$ at's type $A$ (type normal) and type $B$ (type en potence ou en équerre), while type $\mathrm{C}$ of the present paper was not noticed by $\mathrm{Caden}$ at. $\mathrm{C}$ a d e n a t did not notice the variations in the lower jaw. Schwarz examined only the upper jaw and regarded type $A$ of the author as the normal condition, calling it "Staffelstellung", while he ascribed the torsion of the lateral incisor germ (type B) to a pathological case requiring clinical treatment. He included the state of type C in "Staffelstelling".

The type can be decided also by the observations of sagittal and frontal sections, because the lateral incisor is cut differently according to the pattern of crowding. In sagittal sections of the jaw, the central incisor is always cut labio-lingually. The cut direction of the lateral incisor, however, is labio-lingual in the case of type $\mathrm{A}$, and mesio-distal in type $B$ and $C$. Fig. $3-A$ is a sagittal section of No. $140(19.6 \mathrm{~cm})$, the germs of the central incisor as well as the lateral incisor are cut labio-lingually. This specimen may be of type A.

A frontal section of the jaw cuts the germs of the lateral incisor mesio-distally in type $A$ and labio-lingually in types $B$ and C. Fig. $3-B$ shows a frontal section of No. $143(23.5 \mathrm{~cm})$, the germ of the central incisor being cut mesio-distally at the lingual portion, while 
the germ of the lateral incisor labio-lingually. This specimen is presumably type $B$. To decide type $B$ or $C$, it suffices to identify the labial and lingual surfaces of the lateral incisor germ. Therefore, the type can be determined also by sagittal and frontal sections. But it is not always easy to identify the type through sagittal or frontal section, because the cut direction of the jaw itself is not always exactly sagittal or frontal. Since the result obtained in sagittal and frontal section is not absolutely trustworthy, it was omitted from the statistical analysis.

The type can be identified also by the observation of reconstructed models. The available models are six in number, listed with the type of arrangement.

\begin{tabular}{|c|c|c|c|}
\hline Fetal month & Serial number & Upper jaw & Lower jaw \\
\hline V & $86(11.4 \mathrm{~cm})$ & & B \\
& $88(13.0 \mathrm{~cm})$ & A & B \\
VI & $25(18.3 \mathrm{~cm})$ & & \\
VII & $140(19.6 \mathrm{~cm})$ & $\mathrm{C}$ & B \\
VIII & $143(23.5 \mathrm{~cm})$ & & B \\
XI & $125(26.5 \mathrm{~cm})$ & $\mathrm{C}$ & \\
\hline
\end{tabular}

2. Relationship of these types to the inclination of the long axis* of the germs.

The types discussed above refer to the rotation of mesio-distal axis around the long axis of a dental germ. Furthermore, the tooth germs are inclined in the labio-lingual as well as mesio-distal directions in the jaw (it is called tilting or tipping in $\mathrm{O} \mathrm{rb}$ a n's Textbook). The tooth germs are generally inclined toward the more mesially located germ, but the author noticed the lateral incisor germs with reverse inclination. That is, some lateral incisor germs are inclined toward the canine germ. Therefore, the author became interested in the problem whether or not the reverse inclination occurred in a certain type of rotation. The relationship of the types of rotation to that of tilting could not be decided through observations of serial sections or of radiograms.

Observed the models of the mandible above listed, the long axis of the lateral incisor germ is more markedly inclined mesio-distally than that of the central incisor germ; the former seems to lean against the central incisor germ in four cases listed above. Obser-

\footnotetext{
* The middle, inciso-cervical line of tooth germ at labial or lingual view.
} 
vations of models of maxillary tooth germs revealed that in No. 88 (type A) and No. 140 (type C) the lateral incisors have normal inclination, while in No. 125 (Fig. 4, 1962) (type C) the long axis of the lateral incisor was inclined rather to canine germ. This relationship could be examined by the the dissection of the jaw with the naked eye. The materials examined with the naked eye are listed below with the type of rotation. In this table, parentheses signify the transitional case; an asterisk signifies the case where the long axis of the lateral incisor germs is inclined toward the canine germ, being reverse to the normal condition.

\begin{tabular}{|c|c|c|c|c|}
\hline No. & $\begin{array}{l}\text { Crown-rumpf } \\
\text { length }(\mathrm{cm})\end{array}$ & Sex & Lower jaw & Upper jaw \\
\hline 1 & 27 & 우 & $B-B$ & $\mathrm{C}-\mathrm{A}$ \\
\hline 2 & 28 & 今 & & $A-C^{*}$ \\
\hline 3 & 33 & $\hat{\delta}$ & $(\mathrm{B})-(\mathrm{C})$ & $A-C$ \\
\hline 4 & 33 & $\hat{\delta}$ & & $c-c$ \\
\hline 5 & 33 & 우 & $B-B$ & $A-C$ \\
\hline 6 & & $\hat{\delta}$ & $B-B$ & $A-A$ \\
\hline 7 & 26 & $\hat{\delta}$ & & \\
\hline 8 & 28 & $\delta$ & (A) & A \\
\hline 9 & 33 & $\hat{\jmath}$ & $B-B^{*}$ & $C-C$ \\
\hline 10 & 34 & $\hat{o}$ & $\mathrm{~B}-(\mathrm{B})$ & $\mathrm{c}-\mathrm{C}$ \\
\hline 11 & 28 & $\hat{\delta}$ & $B-B$ & $(A)-(A)$ \\
\hline 12 & 32 & $\hat{\delta}$ & $\mathrm{C}-\mathrm{C}$ & $\mathrm{A}-\mathrm{A}$ \\
\hline 13 & 34 & 우 & $B-B$ & $\mathrm{C}-\mathrm{A}$ \\
\hline 14 & 34 & $\delta$ & & $A^{*}-(A)$ \\
\hline 15 & 35 & 우 & $A-C$ & $\mathrm{C}-(\mathrm{C})$ \\
\hline
\end{tabular}

As for the mandibula, only one (No. 9) out of 19 cases of type $B$ (4 cases in the model and 15 cases in the dissection) represented the lateral incisor with inclination reverse to the normal condition. In 2 cases of type $\mathrm{A}$ and 4 cases of type $\mathrm{C}$, the reverse inclination could not be found. The results were summarized as follows :

\begin{tabular}{|l|c|c|c}
\hline & $\mathrm{B}(19)$ & $\mathrm{A}(2)$ & $\mathrm{C}(4)$ \\
\hline Normal inclin. & 18 & 2 & 4 \\
Reverse inclin. & 1 & 0 & 0 \\
\hline
\end{tabular}

In the maxilla, the superposition of the central and the lateral incisor germs is very clear, as shown in Fig. 3-A. The lateral incisor is located more superficially, that is, the labio-lingual inclination of 
long axis is greater in the lateral incisor than in the central. The result obtained through the macroscopic observations of the dissected jaws was added to that obtained through the observations of models. In 2 out of 15 cases of type A (1 case of model plus 14 cases of the naked eye observations), the inclination of the lateral incisor was reverse. In 2 out of 15 cases of type $C$ ( 2 cases in model and 13 cases in the naked eye observations), the lateral incisor was inclined to the canine. Type B was not found.

\begin{tabular}{|l|c|c|c|}
\hline & A (15) & B (0) & C (15) \\
\hline Normal inclin. & 13 & 0 & 13 \\
Reverse inclin. & 2 & 0 & 2 \\
\hline
\end{tabular}

The type of rotation are apparently not related to the type of inclination of tooth germ.

3. The problem whether or not these types of rotation are based on individual variations. The incidence of these types of rotation.

$\mathrm{C}$ a denat who studied also the postnatal specimens was of opinion that these varieties were not caused by individual characters, but the type $B$ changed into type A during the course of development. However, the author can not but keep holding an opposite opinion that these types belong to individual variation. The reasons are;

1) As pointed out in the previous paper (1956), the pattern of crowding is formed very early by the differences in the direction of the epithelial ingrowth.

2) As shown in the above tables (page 2, 3 and 5), the types differ in some cases between right and left sides of the same jaws. This fact is unreasonable, if these types are based on developmental phase, since the jaws of both sides should be nearly in the same developmental stage.

3) The frequency of occurrence of these types is tabulated in every 2 months as follows:

\begin{tabular}{|c|c|c|c|c|c|c|c|c|c|}
\hline \multicolumn{2}{|c|}{ Fetal month } & \multicolumn{4}{|c|}{ Upper jaw } & \multicolumn{4}{|c|}{ Lower jaw } \\
\hline & & A & Non-A & (B & C) & A & B & C & \\
\hline $\mathrm{V}$ & VI & 13 & 8 & $(2$ & 6) / 21 & 2 & 17 & 1 & $/ 20$ \\
\hline VII & VIII & 15 & 6 & $(1$ & 5) $/ 21$ & 1 & 19 & 3 & $/ 23$ \\
\hline IX & $\mathrm{X}$ & 10 & 11 & $(4$ & 7) $/ 21$ & 1 & 18 & 1 & $/ 20$ \\
\hline \multicolumn{2}{|c|}{ total } & 38 & 25 & (7 & 18) /63 & 4 & 54 & 5 & 163 \\
\hline
\end{tabular}


If the type is based on developmental variation, the incidence of type A must increase with advancing age. The differences in incidence of type $A$ as to the upper jaw were analysed with $\chi^{2}$-test. These differences by fetal periods were statistically non-significant $(\mathrm{P}>0.5)$.

Now that these variations are confirmed to be individual ones, the incidence of each type regardless of fetal period is shown in the following table.

\begin{tabular}{|c|c|c|}
\hline Type & Upper jaw (63 cases) & Lower jaw (63 cases) \\
\hline A & $38(60 \%)$ & $4(6 \%)$ \\
B & $7(11 \%)$ & $54(86 \%)$ \\
C & $18(29 \%)$ & $5(8 \%)$ \\
\hline
\end{tabular}

Symmetric and asymmetric occurrence of the types.

\begin{tabular}{|c|c|c|c|c|}
\hline \multicolumn{2}{|c|}{ Upper jaw (26 cases) } & \multicolumn{3}{|c|}{ Lower jaw (24 cases) } \\
\hline Symmetric & $18(69 \%)$ & & 19 & $(79 \%)$ \\
\hline$A-A$ & 12 & $A-A$ & 1 & \\
\hline $\mathrm{B}-\mathrm{B}$ & 3 & $B-B$ & 18 & \\
\hline $\mathrm{C}-\mathrm{C}$ & 3 & & & \\
\hline Asymmetric & $8(31 \%)$ & & 5 & $(21 \%)$ \\
\hline \multirow[t]{2}{*}{$\mathrm{A}-\mathrm{C}$} & 8 & $A-B$ & 3 & \\
\hline & & $B-C$ & 2 & \\
\hline
\end{tabular}

The frequency of types $\mathrm{A}$ and $\mathrm{C}$ is significantly higher in the upper jaw $(\mathrm{P}<.01)$, and the incidence of type $\mathrm{B}$ is significantly higher in the lower jaw $(\mathrm{P}<.01)$.

\section{Conclusion and Résumé}

There are three types in the pattern of crowding of anterior tooth germs in the fetal life; preferably, called type A, B and C. In type $A$ the lateral incisor germ is located as a whole on the lingual side, in types $B$ and $C$, the lateral incisor germ is rotated to the central incisor germ, but the mesial end in type $B$ and the distal end in type $C$ were situated on the $i_{1}-c$ line. (Figs. 1 and 2)

These variaties of rotation are based on individual differences. In the maxilla, type $\mathrm{A}$ is most common $(60 \%)$ followed by type $\mathrm{C}$ (29\%) and type B (11\%). In the mandible, almost all belong to type $\mathrm{B}(86 \%)$, the other types are rare. 
The author wishes to express his gratitude to Dr. H. M a eda, Professor of Public Health, Tokyo Med. and Dent. Univ., for his suggestion in statistical treatment of the data and to Dr. H. Terada, Department of Anatomy, University of Tokyo Faculty of Medicine for his advice in preparing English manuscript.

\section{Bibliography}

$\mathrm{Cadenat}, \mathrm{H}$. Problèmes du rangement de l'arcade temporaire. Cahiers odonto-stomatologiques, 19-44, 1952.

O o ë, T. On the Development of Position of the Tooth Germs in the Human Deciduous Front Teeth. Okajimas Fol. anat. jap., 28 : 317-340, 1956.

- On the Development of Position of the Human Deciduous Molar Germs in the Latter Half of the Fetal Life. Okajimas Fol. anat. jap., 38: 51-71, 1962.

- and Nom a ta, N. Mesio-distal Growth of the Deciduous Front Tooth Germs in Man. Bul. Tokyo Med. and Dent. Univ., 10: 513-522, 1963.

$\mathrm{Schwar}$, M. Die Ontogenie des menschlichen Gebisses in ihrer Beziehungen zur Orthodontik, Fschr. Orthod., 3: 130-151, 251-259, 1933.

S i c her, H. ed., Orban's Oral Histology and Embryology. 5th ed., C. V. Mosby, Saint Louis, p. 304, 1962.

\section{Explanation of Plate}

Fig. 1. Three types in the arrangement of maxillary anterior tooth germs. Horizontal sections. $\times 4$. A. No. $50(23.0 \mathrm{~cm})$, B. No. $63(26.0 \mathrm{~cm})$, C. No. $66(26.5 \mathrm{~cm})$.

Fig. 2. Three types in the arrangement of mandibular anterior tooth germs. Horizontal sections. $\times 4$. A. No. $65(29.5 \mathrm{~cm})$, B. No. $62(28.0 \mathrm{~cm})$, C. No. $48(25.0 \mathrm{~cm})$.

Fig. 3. A. A sagittal section of the maxillary jaw, No. $140(19.6 \mathrm{~cm})$. The germs $i_{1}$ as well as $\dot{i}_{2}$ are cut in labio-lingual direction. Probably type A. $\times 12$. B. A frontal section of the mandibular jaw, No. $143(23.5 \mathrm{~cm})$. The germ $i_{1}$ is cut mesio-distally while $\mathrm{i}_{2}$ labio-lingually. Presumably type $\mathrm{B} . \quad \times 12$. 
Plate

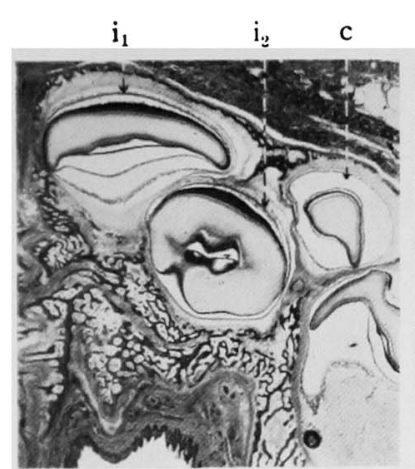

A

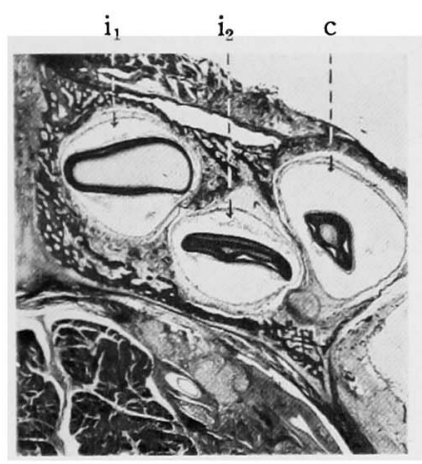

A

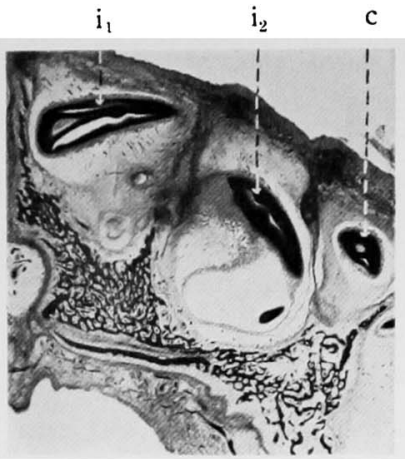

B

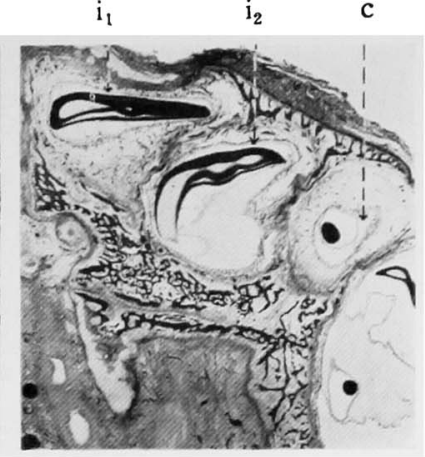

C

Fig. 1.

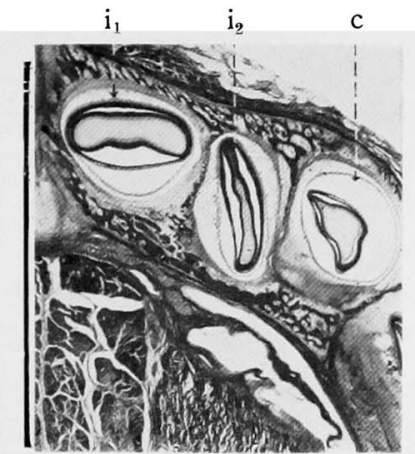

B

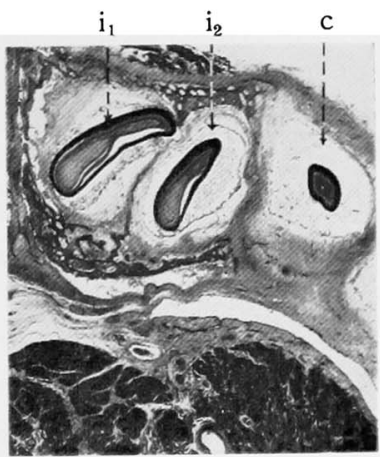

C

Fig. 2.
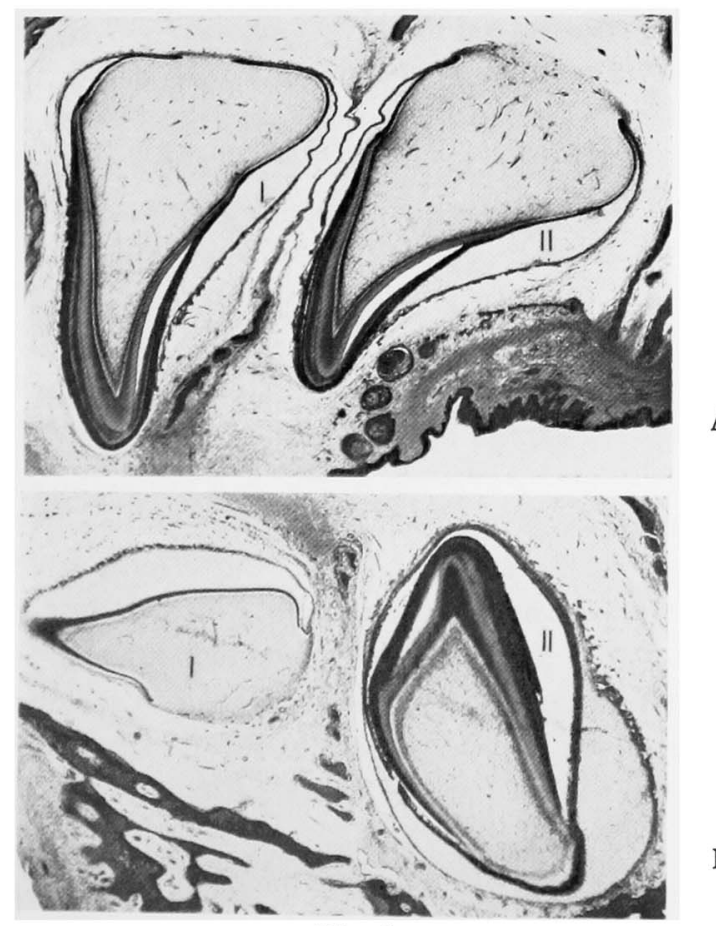

Fig. 3. 